\title{
Problem, Progress and Prospect of Green Building as a means of Sustainable Urbanization with special reference to Guwahati City of Assam
}

\author{
Gunajit Sarma \\ Assistant Professor in Economics,Department of Humanities and Social Sciences, Central Institute of \\ Technology, Kokrajhar BTAD, Assam - 783370 (India)
}

\section{Introduction}

With increasing the modernization, the rate of urbanization has been also increase throughout the world. As a result of urbanization the size of population is parallely enhanced in cities, which leads to construction of great number of multistoried buildings. All of these facts and circumstances creates not only environmental pollution, but also increases the cost, energy consumption and use of natural resources. Hence, the present eco -friendly concept of building called green building becomes immensely important in order to achieve sustainable urbanization. So, this paper mainly attempt to identify various problems emerged during the course of construction of a huge number of building in Guwahati city of Assam , such as economically inefficiency in the use of resource such as air, water and soil, fail to maintain natural resources, fail to ensure social equity in the distribution of developmental benefits and costs . So, to solve this problem Green Building is the only way to maintain better urbanization in Guwahati city of Assam. Further the paper focuses the present level of progress of Green Building concept amongst the builders of the city under study. Considering its needs, the study highlights some future prospects of green building in the Guwahati city as how the systematic implementation of green building concept can be able to achieve sustainable urbanization in the city. The study attempt to discuss as how the green building depletes as little of the natural resources during its construction and operation. The aim of green building design is to minimize the demand on non-renewable resources and maximize the utilization of efficiency of these resources when in use. Further study analyses as how the design efficiency, energy efficiency, water efficiency, material efficiency are applicable in the construction of green building. In addition to the above the study also try to discuss how can green building became cost effective and how can it became the panacea of global warming. If we are able to take proper initiative to growth of green building than green building can became the most important techniques of environment friendly urbanization in India. Therefore, the green building concept has utmost importance to provide enough protection to our earth from global warming as well as it became the path of sustainable development.

\section{Location and Limitation of the Study:}

The study concentrates only on the Guwahati city of Assam. The Guwahati city is the gateway of North-Eastern Region of India as well as it is the capital city of Assam. At present the population of Guwahat is estimated as 1584342.As a Capital city of Assam, the population has been increasing day by day. Consequently a great number of multistoried buildings have been constructed. The study is linked only on those aspects of multistoried building which don't adopt due to green building concept and so study deals with the problem emerged from those building in connection of sustainable urbanization.

\section{Objective of the Study:}

The basic objective of the study is to establish the concept of green building as a tool for achieving sustainable urbanization. The studies will emphasis as how by virtue of implementing the concept of green building, maximum peace, comfort and benefits can be gained with minimum cost and effort in attaining sustainable urbanization. In doing so , the following specific objective have been taken under study. To analyse various benefits of green building that can be scientifically gained in Guwahati city. To identify major problems that stand on the way of popularization and implementation of green building concept as a means of achieving sustainable urbanization in Guwahati city and to examine the present progress and future prospect of green building in Guwahati city.

\section{Discussion of the Study:}

The concept of green building can play a vital role in achieving sustainable urbanization in Guwahati city.Inspite of having ample contribution towards sustainable urbanization, still the green building concept is 
not implemented well in case of Guwahati city. Consequently a sizeable number of problem have been emerged ,which include economic inefficiency is use of resources such as air, water and soil, fail to maintain natural resources stock at as above present level, fail to ensure social equity in the distribution of developmental benefit and cost and fail to avoid unnecessary foreclosure of future development options. All of above circumstances warrant a careful research work on the topic referred to here. Hence this study certainly will provide some effective guidelines to establish green building concept as an effective means for achieving sustainable urbanization in Guwahati. Considering this need, the present study aims at discussing the significance, position of progress and future prospect of green building concept with special reference to Guwahati city.

Building has major environmental impact over their entire life cycle. Resources such as ground cover, forests, water and energy are depleted to construct and operate buildings. Resource intensive materials provide the buildings envelop and land scapping add beauty to it in turn using up water and pesticides to maintain it. Energy consumption system for lighting, space conditioning and water heating provide to its occupants. Water is a vital resource for the occupants, which get consumed continuously during building construction and operation. Several building processes and occupant functions generate large amount of waste. Thus buildings are one of the major pollutants that affect urban air quality and contribute to climate change. But we cannot ignore the construction process of building because without infrastructural facility urbanization is impossible. Hence to design a green building, the essence, of which would be to address all these issues in an integrated and scientific manner. The term green building is also known as sustainable building is the practice of creating structures and using processes that are environmentally responsible and resource efficient throughout a buildings life cycle from sitting to design, construction, operation, maintenance, renovation and demolition. A green building uses less energy, water and natural resources, create less waste and is healthier for the people living inside compared to a standard living. A green building is an environmentally sustainable building, designed, constructed and operated to a minimize the total environmental impacts. According to Indian Green Building Council (IGBC) "A green building uses less energy, water and natural resources, creates less waste and is healthier for the people living inside compared to a standard building."A green building is also known as a sustainable building, is structure that is designed, built, renovated, operated or reused in an ecological and resource efficient manner.

The green building depletes as little of the natural resources during its construction and operation. The aim of green building design is to: minimize the demand on non-renewable resources and maximize the utilization efficiency of these resources when in use. Maximize, reuse and recycling of available resources and utilization of renewable resources. It maximizes the use of efficient building materials and construction practices, optimizes the use of on- site sources and sinks by bio- climate architectural practices, uses minimum energy to power itself, uses efficient equipment to meet its lighting, air-conditioning and other needs, maximizes the use of renewable sources of energy and uses efficient waste and water management practices. It is evolve through a design process that requires all concerned the architect and landscape designer and the air conditioning, electrical, plumbing and energy consultants to work as a team to address all aspects of building and system planning, design, construction and operation. They critically evaluate the impacts of each design decision on the environment and arrive at viable design solutions to minimize the negative impacts and enhance the positive impacts on the environment.

In recent years the world has seen a surge of people who are concerned by the environment, as nicely as firms who are engaged in corporate social responsibility. There are numerous methods to lessen environment impact. Green building is one way to lessen resource consumption and minimize lengthy term cost. There are six principles of green building and objective is to optimize at least one of them like design efficiency, energy efficiency, water efficiency, material efficiency, indoor air top quality and waste reduction. Sustainable building evidently demands creativity, fantastic planning and of course resourcefulness. But in the lengthy run it, provides decreased costs and more protection for the planet and if we are able to the proper initiative than green building can became the most important techniques of environment friendly urbanization in India.

\section{Importance of Green Building:}

1. Economic Importance: A common impression about green building is that the green premium is too expensive to be considered economically feasible. However; studies have shown that the costs of green buildings are not substantially higher than the regular development project .Higher construction costs can generally be avoided by the inclusion of green design from the outset of the project.

2. Reduced energy consumption: The resource efficiency provided by green design and technology leads to drastic reductions in operation costs that quickly recoup any additional project costs and continue to offer dramatic long -term savings. Money previously directed towards utility costs may be used for other purpose.40$50 \%$ less energy by minimized building energy demand through solar passive design, use of efficient building system and maximum use of renewable energy. Reduced energy consumption means lower electricity bills and less dependence on non -renewable resources. Sustainable home use solar hot water systems, passive design 
principles that carefully place windows and doors to reduce, heating and cooling costs by capturing the sun and breezes, roof ,ceiling and wall insulation to keep the heart in during winter and out in summer .Thermal mass keep the house warmer in winter and cooler in summer.

3.Reduce Water Consumption : In green building about $30 \%$ less water required by reducing irrigation water requirement, use of efficient fixtures, rain water harvesting, waste water treatment on site, recycle and reuse of water .

4. Cost efficient to run: An environmentally sustainable building can reduce household running cost by up to $60 \%$ and repairs and ongoing maintenance costs are reduce through the use of low maintenance materials.

5. Reduce greenhouse gas emissions: Pollutants released by fossil fuel fired electricity contribute to global climate change, because air quality issues such as acid rain which are dangerous for human health. Green building techniques like solar powering increase energy efficiency and reduce harmful emissions. The sustainable house uses less energy .Using less energy generated by coal fired power station means greenhouse gas emission is reduced. Green house gases prevent heat from escaping from the earth's atmosphere resulting in global warming and climate change.

Urbanization and its allied process have made great impact on the environment of major cities of India. It is quite imperative in this very changing scenario to provide in advance accurately the urban planning and design to meet this requirement because it is not always possible to project the urban growth accurately. Like all major cities of India, Guwahati is also faced with similar problem, for which there is always conflict between development and environmental degradation. It is always a debatable question how to maintain proper balance between urban development and resultant issues of environmental degradation. According to a survey done by a UK media outlet, Guwahati is among the 100 fastest growing cities of the world and is the $5^{\text {th }}$ fastest growing among Indian cities. However, the exponential increase in population and growth over the year has created enormous pressures on its environment, availability of land and infrastructure. As a result of this, Guwahati faces a major crisis in the urban landscape in the form of disrupted natural ecosystem, annual flooding, absence of basic infrastructure and non-cohesive built form. In this regard green building can became the panacea of sustainable urbanization. Therefore, green building construction is becoming very popular topic in current culture and it should be. So, government should give the importance to popularize this concept. But in our study we have seen that in Guwahati city only few builders have used the techniques of green building. So we should have try to popularize the concept of green building for maintain the environment friendly urbanization in Guwahati city of Assam.

\section{Conclusion:}

Global warming is a serious problem facing the world today as well as the world in the future. In order to stop this problem, society must change. Making buildings green would greatly impact this problem. There are many ways for this to be done and move ways are being developed rapidly. New development is made every day in the field of engineering that are meant to save energy and protect the environment. This is very important time to be conscious of energy consumption, due to global warming. Naturally there will be experts constantly creating new technologies in this field, but another big question is whether there should be rules and regulations that force people to create or use green engineering products. While green building construction may appear costly for consumers, new development in the engineering field is providing increasingly cost effective solutions. Although present day practices in green building construction are important, the real success lies with the future. The future is what will transform the entire world into a place that is self constructive, rather than destructive. Even more beneficial than new technologies arising is the improving of existing technologies to make them greener, more user friendly and more cost efficient. So we think that to protect our environment we have to take the initiative to popularize the concept of green building.

Green or environmentally friendly, building construction is becoming a very popular topic in current culture and it should be. New development is made every day in the field of engineering that are meant to save energy and protect environment. Therefore, the present day practices in green building construction are important because the success lies with the future. The future is what will transform the entire world into a place that is self-constructive, rather than destructive. Even more beneficial than new technologies arising is the improving of existing technologies to make them greener , more user-friendly and more cost efficient.Therfore, to attain the sustainable urbanization in Guwahati city government should give the importance and take necessary action to popularize the concept of green building as well as help us to achieve the Sustainable development in India.

\section{References}

[1]. P.K. Dhar - Urbanisation : Its challenges \& Environmental Degradation -EBH Publishers, Guwahati ,2013

[2]. R.Ramchandra-Urbanization and Urban System in India -Oxford Press

[3]. Charles D. Kolstad-Environmental Economics-Oxford Press

[4]. P.K. Dhar -Indian Economy -Kalyani Publishers ,New-Delhi ,2009 
[5]. Statistical Handbook of Assam ,2012 -Published by Department of Economics and Statistics , Assam

[6]. K chawwick, Green Building Construction, Blue Ridge Virtual Governor's school ,www.important/greeb building.com

[7]. www.ci.chi/environment/green Tech/sub.com

[8]. www.igbc.in.com

[9]. www.worldbc.org.com

[10]. www.urbanpeek.com

[11]. www.greenbuildingsindia.com

[12]. R. Keles, Sustainable urbanization and its policy implication, www.ciheam.org.article

[13]. Piece T T and Habitat, Sustainable Urbanization, UN System Task Team, U 